\title{
HONORING THE
}
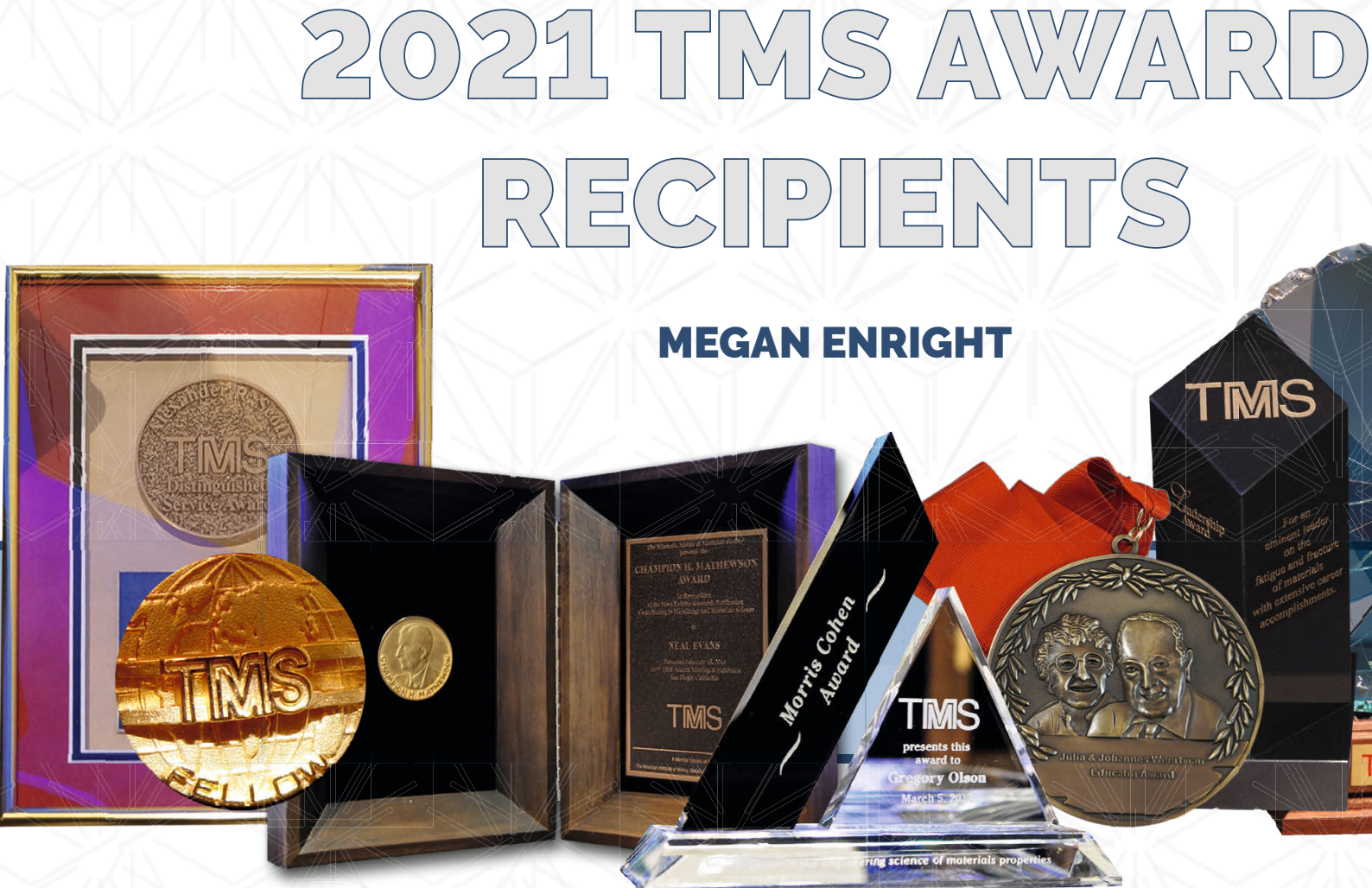

\section{MEGAN ENRIGHT}

The awards conferred by TMS have a crucial role in acknowledging the hard work, dedication, and success of members of the minerals, metals, and materials community. These honors span the full gambit of career stages by recognizing everything from outstanding lifetime contributions to the field to those whose careers are just getting started. Recipients gain well-deserved recognition and aid in the advancement of the entire community by helping to grow careers, providing opportunities to share knowledge, and inspiring others to continue to reach for new heights.

This article highlights the Society-level awards which will be conferred during the TMS-AIME Awards Ceremony at the TMS 2021 Annual Meeting \& Exhibition (TMS2021). All annual meeting registrants are invited to attend this distinguished ceremony to support the 2021 honorees. Most division-level awards will be presented during recognition programs scheduled throughout TMS2021, many of which are also open to all attendees. Visit www.tms.org/TMS2021 for additional information.

\section{Nominate for TMS Awards by April 1}

Do you have a colleague who has made a significant impact on their field? Have they been of great service to their community or to TMS? Honor their contributions and recognize their work by nominating them for a 2022 TMS award.

The nomination deadline for most 2022 TMS awards is April 1, 2021.

Visit awards.tms.org to explore the many honors and awards available through TMS and to learn more about the nomination process. For additional information, contact Deborah Hixon, TMS Awards Program Administrator, at hixon@tms.org. 


\section{SOCIETY AWARDS}

\section{TMS FELLOWS}

The class of Fellow is TMS's highest honor. To be inducted, a candidate must be recognized as the leading authority and contributor to the practice of metallurgy, materials science, and technology, with strong consideration given for outstanding service to the Society.

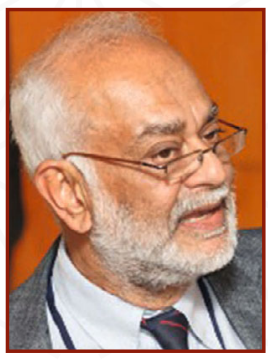

\section{Dipankar Banerjee} Professor, Indian Institute of Science Citation: For seminal contributions to the understanding of titanium and intermetallic alloys and for distinguished international leadership.

"I am deeply honored by this award from TMS. It represents an international outreach of TMS that we recognize as one of its significant strengths as a Society. TMS meetings, which I attend quite regularly, are a wonderful melting pot and opportunity to meet and interact with a truly international community of materials scientists. At a more personal level, I have been privileged to have been mentored by many in my early career and continue to collaborate in more recent years with many in the United States. This award is also a recognition of the work I have been fortunate to do through these interactions."

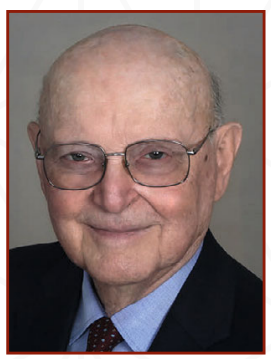

\section{Raymond Decker}

\section{President, NanoMag LLC}

Citation: For pioneering the invention, seminal development, and commercialization of maraging steels, superalloys, thixomolding, and bioresorbable magnesium implants. "I have benefitted from 70 years of membership in TMS, having joined as a student member in 1950. At that time the relationship of properties to processing and microstructure was primitive compared to today. For example, dislocations were not mentioned in any of my undergraduate lectures or textbooks. Since then, TMS has been my learning machine to gain a working knowledge of dislocations and strengthening mechanisms in alloys - for use in inventing Ni-based superalloys, maraging steels, thixomolding and bioabsorbable $\mathrm{Mg}$ implants. It is extra special to receive this award from a Society that contributed so much to my results."

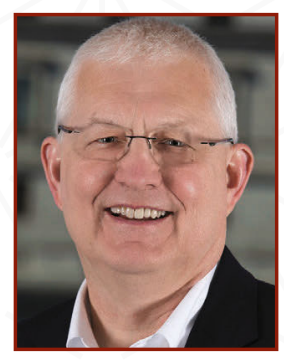

\section{David DeYoung}

Retired, Alcoa

Citation: For technical and scientific leadership within Alcoa and to the broader aluminum technical community. For service to TMS and our professional community.

"Throughout my career, TMS has provided tremendous learning opportunities and these have always exceeded my expectations. Each involvement as a volunteer has invariably turned out to be another development experience. It is truly an honor to be elected a TMS Fellow, and I am humbled to have been considered and selected by colleagues in our field."

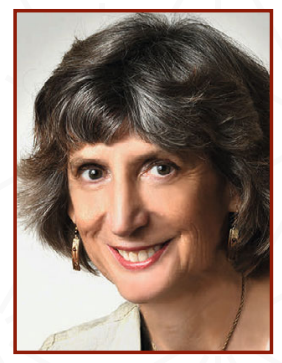

\section{Fiona Doyle} Professor, University of California, Berkeley Citation: For seminal contributions in the practice of innovative hydrometallurgical processing and technologies including materials extraction, purification, environmentally benign processing and remediation, synthesis, and fundamental modeling.

"TMS has been vital to my professional success, both as a source of cutting-edge technical material, and as a professional community where I found friends and mentors and learned indispensable skills. I have always felt welcome and valued - something for which many female engineers of my generation had to struggle. The list of living and deceased TMS Fellows is a who's who of intellectual giants whose contributions have transformed the broad field of materials science and engineering. I feel truly humbled and indescribably honored to be joining their ranks."

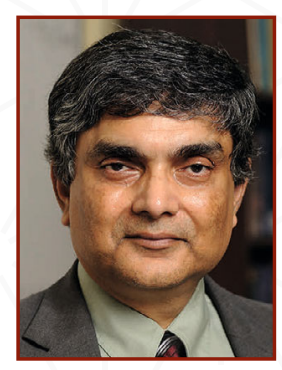

\section{Somnath Ghosh}

Michael G. Callas Chair Professor, Johns Hopkins University Citation: For outstanding visionary contributions to the fields of multiscale materials modeling including ICME, and for sustained ambassadorship of materials engineering across various technical communities.

"I am truly humbled by my selection to the rank of TMS Fellow. I consider this to be one of the highest honors in my professional career. TMS is one of the best professional societies that I have been associated with in my academic career. It has given me the opportunity to interact with some of the best minds in the materials field, who have inspired me with their vision and vibrant intellectual contributions. With this award, I feel lucky to join a distinguished group of colleagues and hope to contribute strongly to the mission of TMS in the coming years." 


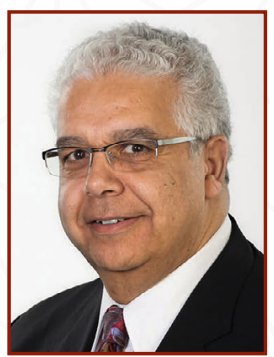

\section{Hani Henein}

Professor, University of Alberta

Citation: For pioneering

developments in pipe-line steels, spray forming, and determination of liquid metal properties; and an outstanding record of publications, international awards, and participation in professional society affairs.

"As a young member, I admired the TMS Fellows as a group of materials science and engineers (MSE) professionals that are the elite of our profession and represent the epitome of excellence in our community. I was amazed at the many MSE theories and principles that were named after them. Never had I thought that one day I would be joining their ranks as a TMS Fellow. I hope my induction as a TMS Fellow inspires today's young TMS members to excel, contribute to the science, engineering, and service of our profession. Such an achievement, although it is identified with one person, represents the efforts of a community over the years to whom I owe a great gratitude. This gratitude extends to TMS, my international professional home, and numerous friends that have enabled my many achievements."

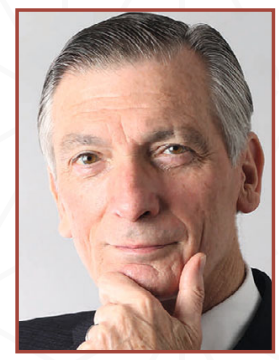

\section{Donald Sadoway}

Professor, Massachusetts

Institute of Technology

Citation: For innovation in electrolytic processing for metals extraction, and for advocacy in resource stewardship, and leadership in materials education.

"I am thrilled to be awarded the distinction of TMS Fellow. For over 40 years I have benefitted from TMS membership through the rich professional interactions at TMS conferences. No question that this helped shape my career, for which I am truly grateful."

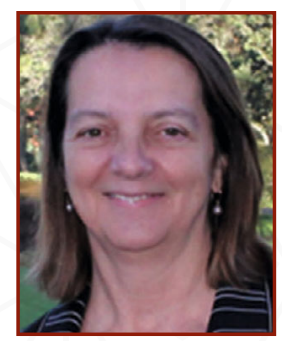

Julie Schoenung

Professor, University of California, Irvine

Citation: For pioneering contributions to the science and engineering of trimodal composites, and for novel applications of green engineering.

"I am very honored and humbled to have been selected as a TMS Fellow. I am very proud to receive this recognition from the TMS community and its leadership, and I hope that my inclusion in the 2021 Class of Fellows will serve as a role model for young women in the materials science and engineering community, and to all scholars who follow a non-traditional path through their career and profession.
I want to thank those who prepared and supported my nomination, and furthermore, I want to share my deepest gratitude to all of my graduate students, postdoctoral fellows, undergraduate students, staff, collaborators, and my own role models - without their hard work, commitment, support, and friendship along the way, my achievements leading to this honor would not have been possible."

\section{BRIMACOMBE MEDALISTS}

This mid-career award recognizes individuals with sustained excellence and achievement in business, technology, education, public policy, or science related to minerals, metals, or materials science and engineering, and a record of continuing service to the profession.

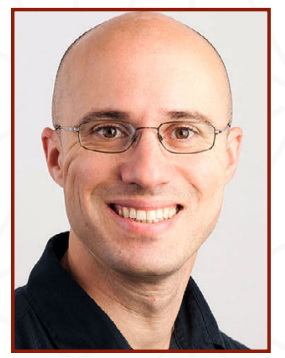

\section{Jamie Kruzic}

Professor and Deputy Head of the School of Mechanical \& Manufacturing Engineering, University of New South Wales Citation: For outstanding contributions to understanding the mechanics and damage tolerance of materials, commitment to professional service and academic leadership, and continued service to TMS.

"I'm very excited and honored to be a TMS Brimacombe Medalist. TMS has supported every step of my career, including a student travel grant and a young leaders award, and has provided me with a professional community to build lifelong collaborations and friendships. It has been a pleasure to volunteer my time to TMS committees, conferences, and journals, and it is humbling to receive this recognition for my research achievements. I look forward to getting involved with TMS in new ways and having a dynamic future together."

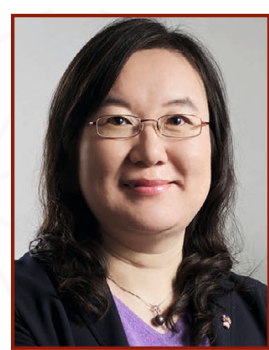

\section{Lei Lu}

Professor, Institute of Metal Research, Chinese Academy of Sciences

Citation: For her significant contribution in metallic materials science, from discovery of highstrength, high-conductivity nanotwinned metals to breakthrough in understanding history-independent cyclic response.

"I feel privileged and very much honored to receive this prestigious TMS award. This will stimulate me further, in my research and also in my activities in the scientific community." 


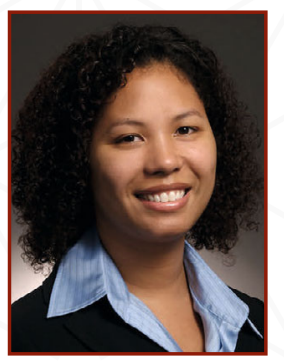

\section{Michele Manuel}

Professor, University of Florida

Citation: For significant contributions

in the integration of systems-based

materials design approaches to light

metals and her meaningful service to

the profession.

"It is truly an honor to be selected for the Brimacombe Medal Award.

Working alongside with distinguished and esteemed TMS colleagues to impact technology, science, engineering, and society at all levels has been a truly enriching and impactful experience, one which has helped me to grow and learn in tremendous and beautifully unpredictable ways. I am thankful for my mentors, colleagues, friends, and especially my family who have continuously supported my career endeavors. I greatly look forward to continuing my professional growth and excellence in the field while maintaining distinguished service to TMS and the profession"

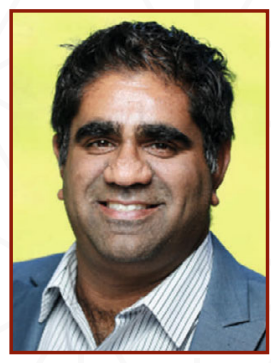

\section{Suveen Mathaudhu}

Assistant Professor, University of California, Riverside

Citation: For exemplary contributions to the science of nanocrystalline materials, education of the public on the impact of materials, and service to the profession.

"I can simplify my feelings on being recognized as a Brimacombe Medalist with one word: gratitude. I'm grateful to the many mentors, colleagues, students, and friends who have motivated me and who have and will continue to be part my journey. And while mere thankfulness can be expressed in words, gratitude is manifested in actions. The energy and significance of this award will fuel me to continue to show my gratitude to our community and its diverse membership for the remainder of my career."

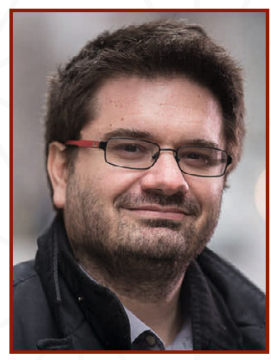

Federico Rosei

Professor \& Director, INRS Centre for Energy, Materials and Telecommunications

Citation: For outstanding research in structure/property relationships of multifunctional materials and for uncommon dedication to service.

"I am honored to receive the 2021

TMS Brimacombe Medal. I am very lucky to be recognized for what I consider sheer pleasure, namely playing with atomic and molecular building blocks and linking their structures with their properties. I owe this success to many people who worked with me or supported me and wish to share it with them, at least in spirit."

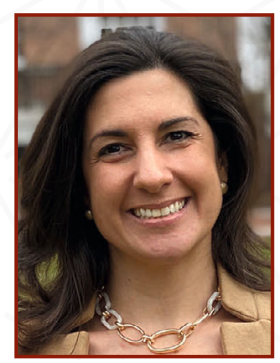

\section{Mitra Taheri}

Professor, Johns Hopkins University Citation: For pioneering contributions to in-situ microscopic and spectroscopic characterization, and her commitment to diversity in mentorship of the next generation.

"TMS was the first society I joined as a student. Since the first TMS meeting that I attended, I have had the opportunity to attend many meetings through various societies and groups; it is TMS, however, that has always felt like 'home' to me. Because of this I'm especially grateful to receive this honor and it's a testament to a Society that not only welcomes members at all levels, but also maintains those relationships over time. I thank my colleagues and friends and look forward to continued engagement within our community."

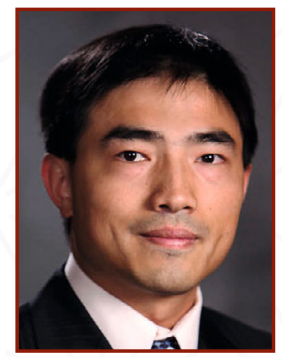

\section{Guihua Yu}

Mike Walker Associate Professor, University of Texas at Austin Citation: For innovations in developing new multifunctional nanostructured materials for significant applications in advanced energy, sustainability, and environmental technologies, and dedicated services to materials community.

"The TMS community is truly special to me, as TMS meetings and activities provide many unique opportunities for researchers working in materials science and engineering to get connected with fellow scientists and engineers in both industry and academia and work together across disciplines to make significant advancement in the materials world to benefit the Society. I look forward to continuing active engagement and contributions to TMS and the broader materials community."

\section{ALEXANDER SCOTT DISTINGUISHED SERVICE AWARD}

Recognizing outstanding contributions to TMS, this award is typically presented for 10 or more years of TMS service in membership development, student chapters, education, and professional affairs, and/or other Society-level activity.

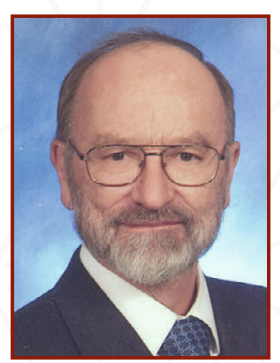

Stanley Howard Professor Emeritus, South Dakota School of Mines and Technology Citation: For passionate, dedicated, exemplary uninterrupted and loyal service to The Minerals, Metals \& Materials Society since 1966.

"As a youth, I dreamed of visiting with a metallurgist to learn more of the subject I loved. So, later being able to be a part of and serving 
a Society of metallurgists and materials and mineral engineers has been a joy. My friends are here at TMS: dear friends who have enriched my journey of exploration and learning. Having never sought positions or honors, I am surprised by the unlikely circumstance that they have somehow found me, but I attribute it entirely to either the kind encouragement, opportunities, or errors of my dear TMS friends. I am honored to be the 2021 face of service to TMS knowing well there are many who serve or have served devotedly and astutely including my friend and the award's namesake, Alex Scott. Lastly and most importantly, were it not for a previous recipient of this award, my former graduate advisor, colleague, and dear friend, I would never have embarked on my TMS odyssey; thank you, John Hager."

\section{JULIA AND JOHANNES WEERTMAN EDUCATOR AWARD}

This award recognizes an individual who has made outstanding contributions to education in metallurgical engineering and/or materials science and engineering.

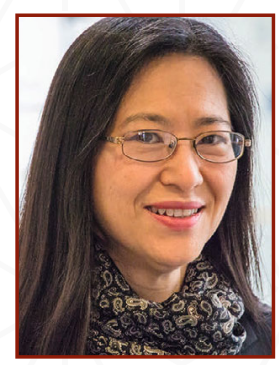

\section{Katsuyo Thornton}

L.H. and F.E. Van Vlack Professor of Materials Science \& Engineering, University of Michigan

Citation: For her dedication to incorporating computational materials science into undergraduate curriculums by leading the development and implementation of the Integrated

Computational Materials Education Workshop.

"It is an incredible honor to receive this award, named after two wonderful, pioneering materials scientists whose legacy continues to live in the materials science community. TMS has been my professional home since I began materials research. It is where I have found a welcoming community that inspires and fosters new, exciting ideas. I am grateful to be part of TMS, where I have benefitted from its culture of inclusion."

\section{LEADERSHIP AWARD}

This award recognizes an individual who has demonstrated outstanding leadership in the national and international materials community.

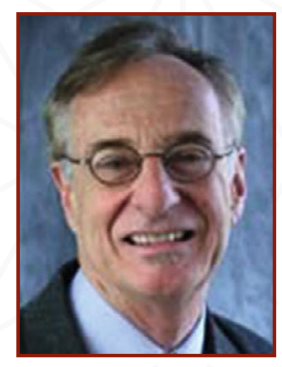

\section{Marc Meyers}

Distinguished Professor of Materials Science, University of California, San Diego

Citation: For outstanding leadership in mechanical behavior of materials, extraordinary creativity, and teaching and mentoring of a large group of students from around the world.

\section{RESEARCH TO INDUSTRIAL PRACTICE AWARD}

This award recognizes an individual who has demonstrated outstanding achievement in transferring research results or findings into commercial production and practical use.

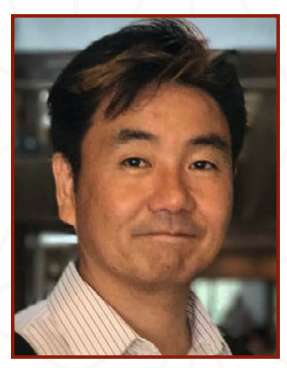

Kazuhiro Nogita Associate Professor and Director, University of Queensland Citation: For establishing the multiple effects of $\mathrm{Ni}$ in $\mathrm{Pb}$-free solder alloys, opening the way for a new generation of high-reliability, thermodynamically stable interconnects. "I am humbled to be receiving this award. I must acknowledge all of those who have contributed to the work of our Centre over recent years for $\mathrm{Pb}$-free solder and electronic packaging research. Having such great industry support as well as being part of the TMS community and benefiting from communication with other excellent researchers has made my research possible and enjoyable. Over the past 20 years I have learned a lot from this community and the TMS annual meeting continues to be a highlight of my year."

\section{BRUCE CHALMERS AWARD}

Honors outstanding contributions to the science and/or technology of materials processing by an individual.

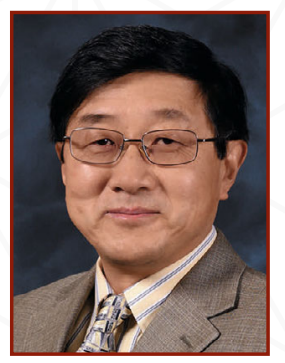

Alan Luo Professor \& Director, The Ohio State University Citation: For his outstanding contributions to light metal processing, alloy development, and automotive applications.

"I am greatly honored to receive this prestigious award and deeply humbled to be associated with its namesake, a pioneer in solidification science, and to join my esteemed colleagues of past awardees. This award recognizes my research in light metals casting and forming, alloy development, and automotive applications. I am grateful for the tremendous support and contributions from my industrial collaborators, university colleagues, and many students and postdocs. I also thank TMS for providing excellent technical meetings and networking opportunities for my research and career development." 


\section{CYRIL STANLEY SMITH AWARD}

This award recognizes outstanding contributions to the science and/or technology of materials structure.

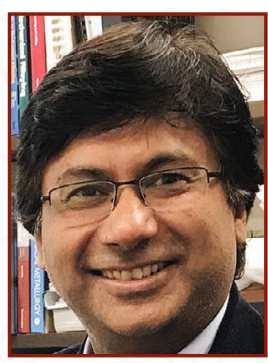

\section{Amit Misra}

Professor, University of Michigan

Citation: For seminal contributions

to the fundamental understanding

of defects, interfaces, and

nanomechanical behavior in

nanolayered and multiphase metallic materials.

"I feel privileged to have been a

TMS member throughout my career in the United States spanning three decades. The opportunities provided by TMS have been significant in my professional development, particularly in fundamental research in structural materials. I feel honored to be recognized with the Cyril Stanley Smith Award and am grateful to the support from my colleagues, friends, and family."

\section{OLEG D. SHERBY AWARD}

This award recognizes an individual, or small group of collaborators, who has made significant contributions to the understanding of the behavior of materials at high temperatures.

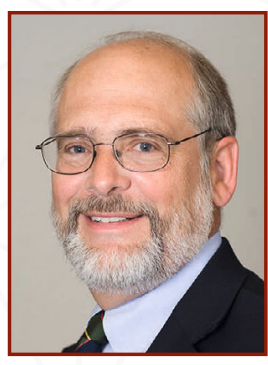

\section{Jeffery Gibeling \\ Professor, University of California, Davis}

Citation: For creating innovative methods to acquire mechanical property data with significant impact on understanding mechanisms of high temperature creep deformation in metals and alloys.

"I am deeply honored to be named the recipient of the 2021 Oleg D. Sherby Award. This award is especially meaningful to me because I knew Oleg Sherby well and learned much from him about high-temperature deformation. His ideas and teaching have had a significant impact on my work in this field, for which I am forever grateful. Oleg Sherby was a warm person with great enthusiasm for materials science and engineering. I especially appreciated his broad perspective on creep deformation as he strove to understand and integrate 'all the data in the world,' as he was fond of saying. One of my favorite presentations was the one I gave at the $2000 \mathrm{TMS}$ Annual Meeting at a symposium honoring Sherby in which I incorporated many concepts I learned from him. Finally, I want to express my appreciation to my nominators and the selection committee for this honor."

\section{WILLIAM HUME-ROTHERY AWARD}

Awarded in recognition of exceptional scholarly contributions to the science of alloys.

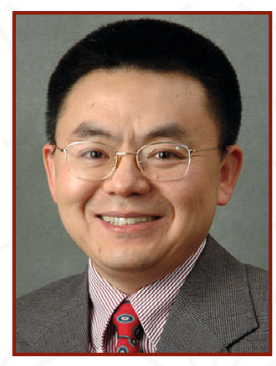

\section{Ji-Cheng (JC) Zhao} Minta Martin Professor and Department Chair, University of Maryland Citation: For development of groundbreaking methodologies for systematic measurements of phasebased properties for the understanding of a very large number of alloy systems.

Presentation Title: "High-Throughput Measurements of Composition-Dependent Properties of Alloy Phases for Accelerated Alloy Design"

\section{INSTITUTE OF METALS LECTURER \& ROBERT FRANKLIN MEHL AWARD}

In receiving this pinnacle award, honorees present a lecture at the TMS annual meeting, which is also published in one of the Metallurgical and Materials Transactions journals. Named in honor of Robert Franklin Mehl, an instrumental force in the fields of metallurgy and materials science and engineering, the award celebrates 100 years in 2021.

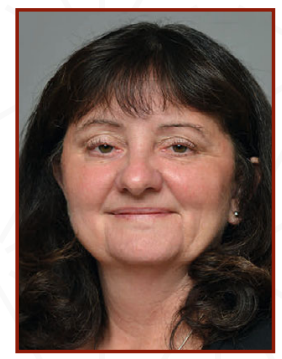
Tresa Pollock Professor, University of California, Santa Barbara Citation: For extraordinary contributions to the improved understanding of high-temperature alloys and coatings. For being an inspirational role model for young engineers of both genders.

"I am deeply honored to be selected to receive this award. It is a heartfelt recognition of my collaborators and my students who aspired to invent new methods to accelerate data gathering for numerous important alloy systems and to perform more systematic study of the science of alloys. It is incredibly heartening for me to have my name associated with previous winners. This award inspires me to continue inventing new methodologies and collecting more critical data to help design new alloys to address the societal needs for a better environment and joyful living." 


\section{ELLEN SWALLOW RICHARDS DIVERSITY AWARD}

This award recognizes an individual who, in the remarkable pioneering spirit of Ellen Swallow Richards, has helped or inspired others to overcome personal, professional, educational, cultural, or institutional adversity to pursue a career in minerals, metals, and/or materials.

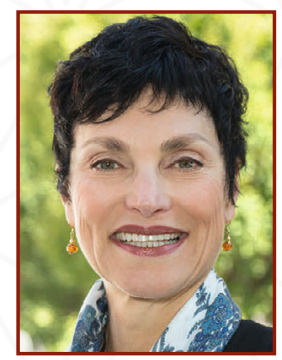

\section{Mary Juhas}

Associate Vice President, The Ohio State University

Citation: For her untiring efforts

at recruitment, retention, and advancement of women in the science, technology, engineering, mathematics, and medicine (STEMM) disciplines.

"We all stand upon the shoulders of Ellen Swallow Richards, a pathfinder, trailblazer, and influencer whose contributions remain relevant and never more important to our global village. It is with great humility that I express my gratitude to Megan Cordill and the awards committee, and especially to Jeffery and Geraldine McCulley Wadsworth for endowing the award. My TMS membership has afforded me the fantastic opportunity to learn, share, and engage with members of the materials science community from academia, government, and industry over many years. While I have been quite pleased to see the face of materials science become increasingly diverse during my career, there is always more work to be done."

\section{FRANK CROSSLEY DIVERSITY AWARD}

Awarded to an individual who has personally overcome personal, professional, educational, cultural, or institutional adversity to pursue a career in minerals, metals, and/or materials.

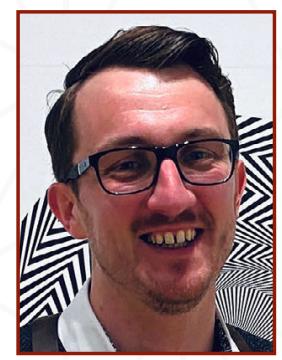

\section{T. Ben Britton}

Reader in Metallurgy and Microscopy/ Associate Professor, Imperial College London/University of British Columbia

Citation: As an $L G B T Q+$ individual, Dr. Britton has overcome barriers to become a world-leading materials scientist and engineer and he fights for increasing equality for all.

"TMS creates and sustains an international community of scientists and engineers, drawing together academics and industrialists via its annual meeting, papers, and digital media. This makes the world smaller and more accessible, enabling us to share ideas and know-how and build friendships across the world. I am especially impressed at the contributions of the TMS Diversity, Equity, and Inclusion Committee and its work to understand and address current and historic imbalances in our community, as well as drawing in more members and enabling us to create a more robust and sustainable community for all. As we all work together, I hope that more people will continue to reflect on their own journey, and look around the room more often to see, and address, instances where conscious, unconscious, and systematic bias create and sustain barriers which limit equal participation for all, especially the most marginalized and those at the start of their careers."

\section{WILLIAM D. NIX AWARD}

Established to honor William D. Nix and his legacy, this award highlights and promotes continued progress and innovation relevant to research into the underlying mechanisms and mechanical behavior of macro-, micro-, and nanoscale materials.

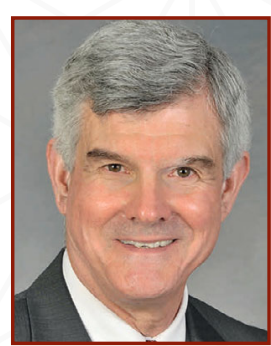

\section{George Pharr}

Professor, Texas A\&M University

Citation: For development of methods for the quantitative determination of material mechanical response by nanoindentation and its use to elucidate fundamental mechanisms of material behavior.

Presentation Title: "Damage

Tolerance in Materials"

"I was thrilled to learn that I have been chosen by TMS as the next recipient of the William D. Nix Award. Knowing well what a giant William Nix has been in materials research and education, it is certainly a tremendous honor. My sincere thanks to TMS and all my materials friends and colleagues who made this possible."

\section{EARLY CAREER FACULTY FELLOW}

This award recognizes an assistant professor for his or her accomplishments that have advanced the academic institution where employed, and for abilities to broaden the technological profile of TMS.

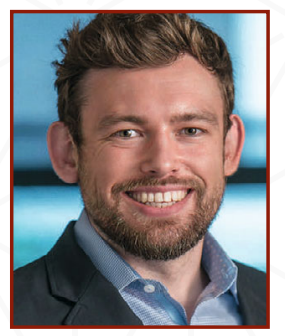

\section{James Pikul Assistant Professor, University of Pennsylvania Presentation Title: "Electrochemical Healing of Metals: A New Way to Repair Additive and Cellular Metals at Room Temperature" \\ "I am honored to be part of TMS and} to further its important mission. I am also very grateful to the TMS Foundation for their support of young professionals. Their efforts enrich the TMS community by fostering a strong and supportive community for young members and early career scientists. Through TMS events, the TMS Foundation catalyzes relationships among professionals from industry, academia, and national laboratories. These diverse interactions create wonderful new ideas that advance engineering, science, and society. I look forward to participating and presenting in the Young Professional Tutorial Luncheon and to continued engagement with the TMS community." 


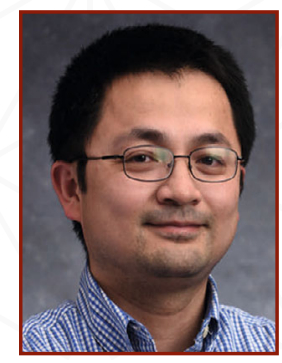

\section{Wei Xiong}

Assistant Professor, University of Pittsburgh

Presentation Title: "Integrated Computational Materials Design for Alloy Additive Manufacturing" "TMS provides a phenomenal platform for junior metallurgists to collaborate with and learn from other researchers and engineers in our community. It also creates unique opportunities for me to extend my network by connecting with peers in the industry, national laboratories, and academia. Since my first TMS annual meeting in 2013, I have learned a lot by giving presentations, organizing symposia, initiating professional development courses, and serving on committees. I am immensely honored to receive this prestigious award and will continue to support various activities organized by TMS. Due to the pandemic, we need to absorb many impacts with high uncertainties this year. I will keep onward with all TMS members, and, together, we expect victory."

\section{FRONTIERS OF MATERIALS AWARD}

This award is given competitively to top-performing early career professionals capable or organizing a Frontiers of Materials event comprising a hot or emergent technical topic at the TMS Annual Meeting \& Exhibition.

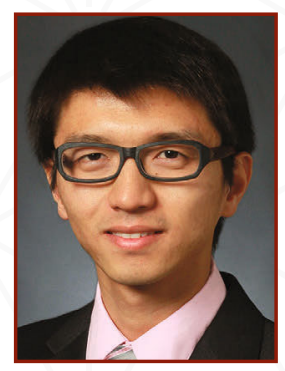

Huanyu (Larry) Cheng Assistant Professor, The Pennsylvania State University Symposium: 2021 Functional Nanomaterials: Translating Innovation into Pioneering Technologies "I greatly benefit from interaction with peer researchers in multiple

fields across the globe. This award provides a once-in-alifetime opportunity for me to meet and interact with the greatest minds in the interdisciplinary research that brings the materials with devices and biomedical applications. It would be an invaluable experience for me to access guidance and advice from the leading experts in person. It is also helpful to showcase some of the great research we have been doing at Penn State and establish new contacts and collaborations in the field, which will help take our research beyond the existing scope and open up new opportunities for my career."

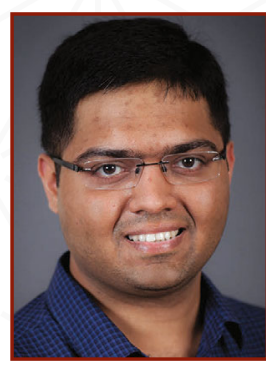

\author{
Deep Jariwala \\ Assistant Professor, \\ University of Pennsylvania \\ Symposium: Low-Dimensional \\ Materials and Interfaces for Next \\ Generation Computing \\ "TMS is one of the oldest \\ professional societies in the world \\ in the broad domain of materials
}

research. It is the first international society that I was aware of, even as a sophomore in college without much knowhow or understanding of the scientific or academic research world. This honor and recognition from TMS at this stage of my career is therefore truly special. I am further thrilled and excited to contribute my expertise, knowledge, and experience to TMS, and to organize a forward-looking symposium in my area of research. I hope this awardrelated symposium will expand the disciplinary horizons of materials and research areas for TMS leading to new collaborations and cross-fertilization of research ideas across the broad spectrum of materials researchers who are TMS members and attendees of the annual meeting."

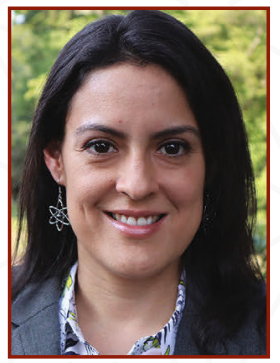

\section{Jessika Rojas-Marin Assistant Professor, Virginia Commonwealth University} Symposium: Radiation Processing of Materials

"Being a member of TMS has always brought significant advantages to my professional development. The annual meetings I have attended were a tremendous educational and professional experience; I have learned from other researchers and have received updates on advances in diverse fields and those of particular interest to me. They have also been a great platform to reconnect with colleagues and meet professionals from different backgrounds. With the highly interdisciplinary scope of TMS in materials science, I have always found a program to share my research through oral and poster presentations with a very positive reception. Not to mention I have enjoyed the excellent student competitions! This award is a great honor and I am highly motivated to bring the topic of radiation processing to TMS. With this award, I aim to highlight the beneficial uses of ionizing radiation for materials manufacturing and processing and motivate a discussion on the potential advances in the field." 


\section{TMS BEST PAPER CONTEST}

This award recognizes student essays on global or national issues as well as technical research papers relating to any field of metallurgy or materials science

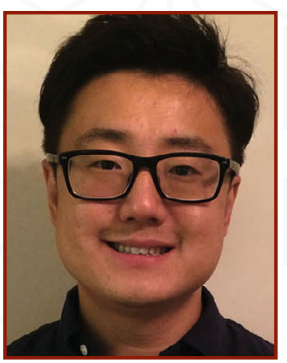
most well-known associations in the minerals, metals, and materials science fields. Thus, it is a great honor for me to be recognized by an outstanding Society with this award. I would like to sincerely thank my advisor, Peter K. Liaw, and my mentors, Saryu Jindal Fensin and Nan Li, for their invaluable support and guidance throughout my scientific research. This award will be a nice springboard for my future career development and help me to boost my confidence and achieve my academic goals."

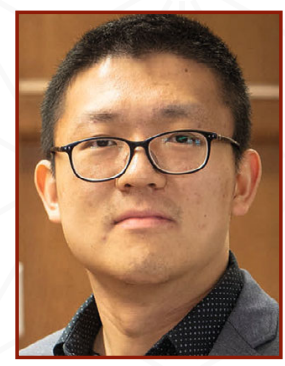

\section{Best Paper Award - Second Place Graduate Zhongxia Shang} Student, Purdue University Paper Title: "He Ion Irradiation Response of a Gradient T91 Steel"

"TMS has provided many valuable opportunities for the materials science and engineering community by connecting scientists and engineers all over the world. Particularly, it benefits young researchers like me most by offering us a worldwide platform to present our exciting and innovative work. As a TMS member, I feel very grateful to accept such a prestigious award. I really enjoy staying in such a professional and friendly community to pursue my academic career goal."

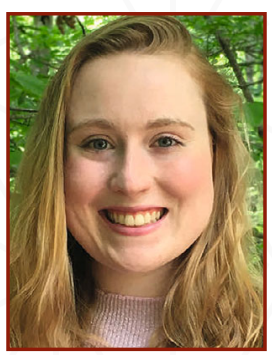

\section{Best Paper Award - First Place Undergraduate Lily Turaski Student, Georgia Institute of Technology Paper: "Thermodynamics and Kinetics of MAPbI3 Perovskite Processing" \\ "TMS and Material Advantage have} made an immense impact on my education and career path. I attended my first TMS annual meeting as a freshman. I loved learning about innovations and discoveries at the forefront of materials research and meeting fellow materials science and engineering students, professors, and industry professionals. That first experience cemented

my love of materials science and ensured I would be a regular conference-goer. Since then, I have had the opportunity to present research posters, participate in the Undergraduate Speaking Contest, and enter the Material Bowl Competition. I am so thankful that TMS, Battelle, and the Functional Materials Division are investing in students like me."

\section{KAUFMAN CALPHAD SCHOLARSHIP}

Awarded through CALPHAD Inc. and the TMS Foundation to sophomore or junior undergraduate students majoring in metallurgical engineering, materials science and engineering, or minerals processing/extraction programs.

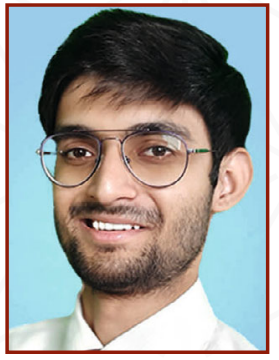

Hrushikesh Sahasrabuddhe Student, Indian Institute of Technology Bombay

"I am deeply honored to receive the Kaufman CALPHAD Scholarship for 2021. TMS and Material

Advantage have enabled me to attend conferences focusing on cutting-edge technology and some high-impact research. After interacting with the students, industry persons, and all other professionals during TMS's webinars and conferences, I am highly motivated and enthusiastic about contributing towards the advancement of materials research. After graduation, I plan to enroll in doctoral studies in the field of mechanical behavior of materials and wish to start an enterprise alongside it. I am sure that this scholarship will help me in realizing my future goals and ambitions!"

\section{AIME AWARDS}

\section{TMS/SME/AIME JAMES DOUGLAS GOLD MEDAL}

Honors distinguished achievement in nonferrous metallurgy, including both the beneficiation of ores and the alloying and utilization of nonferrous metals. This award is administered through TMS's Extraction \& Processing Division (EPD) and the Society for Mining, Metallurgy \& Exploration's (SME) Minerals \& Metallurgical Processing Division (MPD).

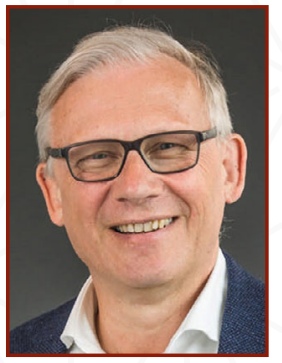

Maurits Van Camp Director Research \& Innovation, Umicore Citation: A visionary leader and entrepreneur who has dedicated his professional life to develop innovative technological solutions and promote collaboration between industry, academia, and governmental organizations. 


\section{AIME CHAMPION H. MATTHEWSON AWARD}

Awarded to the author(s) of a paper, or a series of closely related papers, representing the most notable contribution to metallurgical science during the period under review.
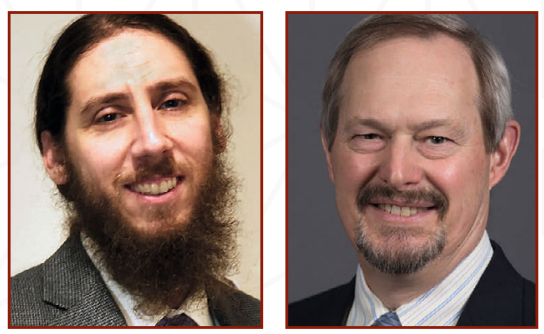

\section{Daniel M.} Field, U.S. Army Combat Capabilities Command, U.S. Army Research Laboratory (left), and

David C. Van

Aken, Curators' Teaching Professor, Missouri University of Science and Technology (right)

Paper: "Dynamic Strain Aging Phenomena and Tensile Response of Medium-Mn TRIP Steel," Metallurgical and Materials Transactions A, April 2018 (Topic Area: Mechanical Behavior).

"TMS has been instrumental in providing the platform for publishing my work. I am thankful for all of the journals and conferences that TMS supports to provide healthy scientific discourse to promote the art and science that is metallurgy. I am thankful for the recognition of this award and all that it signifies about my work and its impact to steel metallurgy," Field said. Van Aken added, "I owe a great debt of gratitude to TMS for their publication and continued recognition of our manganese alloyed steel research. I would also like to acknowledge Missouri University of Science and Technology for giving me an opportunity to have a balanced career in both teaching and research. Excellence in teaching garnered some truly talented students to my research group and their work has been recognized by these awards."
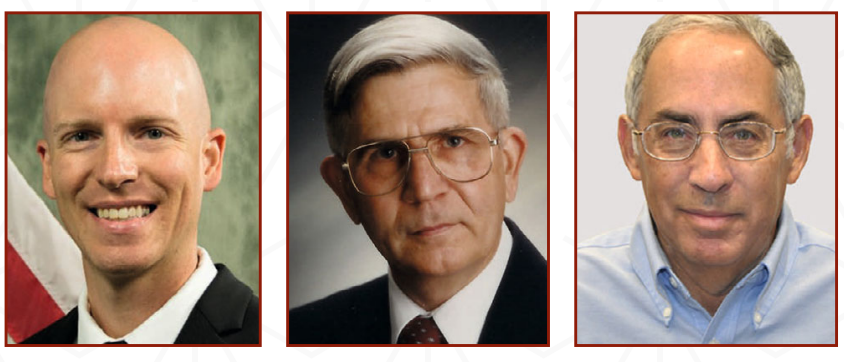

Pictured, left to right: Adam L. Pilchak, Senior Materials Research Engineer, U.S. Air Force Research Laboratory (AFRL); Gordon A. Sargent, Dean Emeritus, University of Dayton/Gordon A. Sargent Consulting; and S. Lee Semiatin, Senior Scientist Emeritus, $A F R L$

Paper: "Early Stages of Microstructure and Texture Evolution during Beta Annealing of Ti-6Al-4V," Metallurgical and Materials Transactions A, March 2018 (Topic Area: Materials Processing).

"I am very grateful to TMS and the awards selection committee for recognizing our paper with this prestigious award. Though my research directions have evolved over the years and my work has shifted from very basic toward very applied science, TMS has consistently remained a place to interact with world-class researchers in every and all aspects of materials science," Pilchak said. "Sharing this award with my co-authors is one of the pinnacles of my career. I first joined TMS as an undergraduate student. These outstanding organizations have been vitally important in the subsequent development of my professional career as an educator and researcher in the complex disciplines of materials science and engineering," Sargent added. "I view Metallurgical and Materials Transactions (MMT) as my 'home' journal and TMS as my 'home' technical society. Having published papers in MMT in each of the five decades of its existence, the Mathewson recognition holds a very special meaning to me. I also wish extend a sincere thanks to the editors and production staff at $M M T$," Semiatin said.

\section{AIME ROBERT LANSING HARDY AWARD}

For more than half a century, this award has recognized professionals under the age of 35 in the broad fields of metallurgy and materials science for exceptional promise of a successful career.

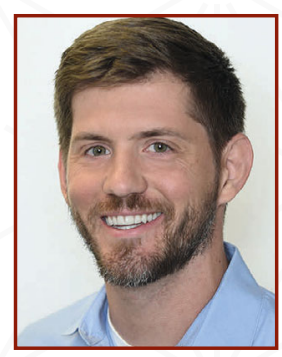

Bryce Meredig Citrine Informatics

Citation: For pioneering work in the use of artificial intelligence to accelerate materials design and discovery.

"I am honored to receive this award, which is a good opportunity to reflect on how much our success depends on investments by others in our growth and goals. I am grateful to have worked with outstanding mentors, colleagues, and collaborators, without whose support my career path would not have been possible. I look forward to continued engagement at the TMS annual meetings, which have featured excellent programming on data-driven materials science for many years now, and with TMS more broadly."

\section{AIME HENRY DEWITT SMITH SCHOLARSHIPS}

This scholarship is awarded to graduate students majoring in mineral, metals, and/or materials engineering. The award aims to advance the mineral industries by assisting students in the pursuit of graduate education in mining,

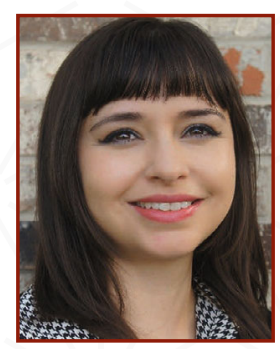
metallurgical, materials, or petroleumrelated disciplines.

\section{Faith Gantz}

Student, University of North Texas "Being a member of TMS and Material Advantage offers valuable opportunities by providing students with resources like travel grants, 
scholarships, and conference experiences. I have been an active member since the start of my graduate career, where I learned of opportunities such as the Henry DeWitt Smith Scholarship. It is a great privilege to win this prestigious award. The benefits will go towards continuing my education in graduate school for a Ph.D. in materials science. My research consists of the characterization, development, and processing of shape memory alloys for aerospace applications. After completing my degree, I plan to continue with R\&D of shape memory alloys or focus on quality control/failure analysis in industry or at a national laboratory."

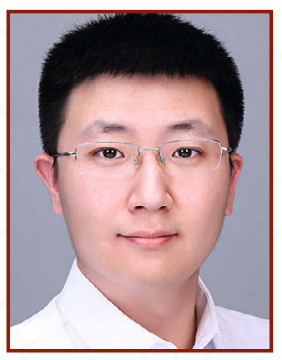

\section{Yang Shen}

Student, Northeastern University

"It's my great honor to receive the TMS/AIME Henry DeWitt Smith Scholarship. I have been a Material Advantage member since 2017 and received a TMS travel grant to attend the TMS 2018 Annual Meeting \& Exhibition which gave me a valuable opportunity to enhance my presentation and communication skills in such a wonderful Society. Currently, I am the chair of the Material Advantage chapter of Northeastern University-China, which has enriched my leadership experiences and strengthened academic communications in different fields. After graduation, I would prefer to join a research team working on physical metallurgy and welding metallurgy. This scholarship is an affirmation of my hard work and will encourage me to keep going in my academic career."

\section{ACTA MATERIALIA AWARDS}

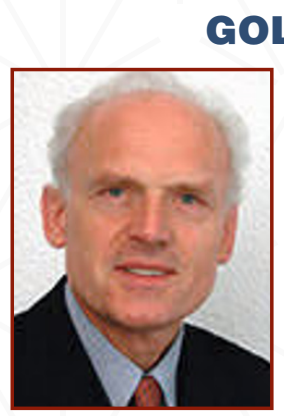

\section{GOLD MEDAL AWARD}

Awarded to a proven leader in materials science and engineering whose research has significantly impacted the development of the discipline.

\section{Guenter Gottstein} Distinguished Senior Professor, RWTH Aachen University

\section{SILVER MEDAL AWARD}

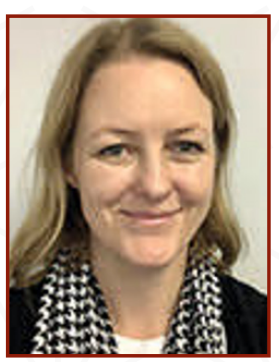

This award honors scientific contributions and leadership from academic, industry, and public sector leaders in the midst of their careers.

\section{Julie Cairney}

Director of Australian Centre for Microscopy and Microanalysis, University of Sydney
HOLLOMON MATERIALS \& SOCIETY AWARD

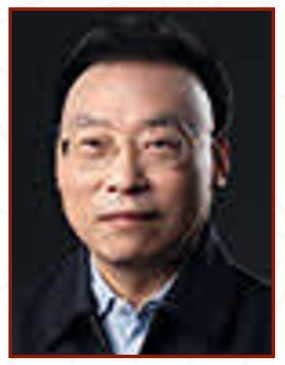

This recognition honors an individual who promotes understanding of the relationship and interactions between materials technology and societal interest or needs.

\section{Qingjie Zhang}

Professor, Wuhan University of Technology

\section{ACTA MATERIALIA UNDERGRADUATE SCHOLARSHIP}

Supported by the generosity of Acta Materialia Inc. and issued under the TMS Foundation, this scholarship is available to undergraduate students majoring in metallurgical engineering, materials science and engineering, or to undergraduate students with a significant interest in the materials area.

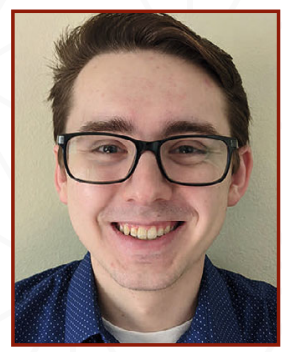

\section{Nicholas D'Attilio} Student, South Dakota School of Mines \& Technology

"I joined Material Advantage during my first semester of college. Through my membership I gained access to a myriad of journals and other professional resources that have proved useful throughout my undergraduate career. Additionally, my membership in Material Advantage provided me the opportunity to attend the 2020 TMS Annual Meeting \& Exhibition in San Diego. Attending the TMS conference was an excellent experience to learn about current research in the materials field and to grow my professional circle. I look forward to graduating in May and am currently searching for jobs. I intend to work in industry for a few years and then return to graduate school."

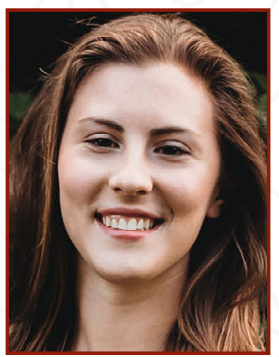

\section{Baily Syring Student, University of Wisconsin-Madison \\ "Involvement in TMS and Material Advantage (MA) have been critical in helping me explore my academic and career interests within materials science. Through the University of Wisconsin-Madison chapter of}

MA, I have been able to connect with other materials science and engineering students as well as professors and other professionals within the materials discipline. I am incredibly grateful to the TMS Scholarship Committee and Acta Materialia Inc. as this scholarship substantially helps the accessibility of my education. After graduation, I plan to begin my professional career in materials science, where I will continue to expand my knowledge of materials." 


\section{MARY FORTUNE GLOBAL DIVERSITY AWARD}

With this distinction, Acta Materialia not only intends to honor outstanding contributions to the field, but also to improve the awareness of the fundamental importance and

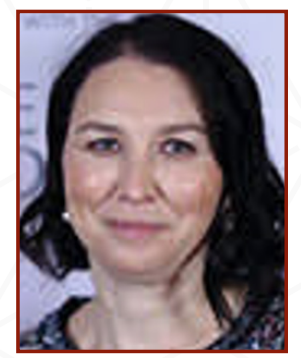
diversity of materials research, both within the community and the public at large.

\section{Katalin Balázsi}

Head of Thin Film Physics

Department, Hungarian Academy of

Sciences

\section{BRIMACOMBE PRIZE}

The Brimacombe Prize was designed to speak symbolically of the achievements of its recipients while perpetuating these attributes that J. Keith Brimacombe set as standards for his own character and career: a creator of new knowledge through research excellence, a visionary and innovator for a better global society, a $\left(\frac{a}{2}\right.$ world ambassador integrating science and technology with creative insight. This award is supported by the Brimacombe Fund, an endowment held by the Vancouver Foundation.

\section{Philippe Jarry}

Technical Expert, Constellium C-TEC

\section{DIVISION AWARDS}

In addition to the many Society-level awards administered by TMS, each of the Society's five divisions provide opportunities for recognition specific to the work performed in their areas of technical interest. More information on each of these awards, as well as quotes and photos from recipients, are available on awards.tms.org.

\section{EXTRACTION \& PROCESSING DIVISION (EPD) DISTINGUISHED LECTURE AWARD}

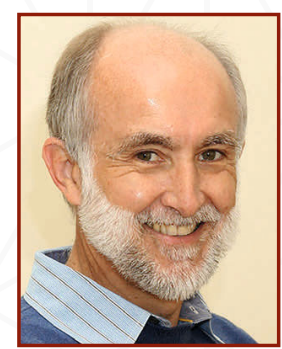

\section{Rodney Jones \\ Consultant, Mintek}

Citation: A researcher in the field of pyrometallurgy for nearly four decades and regarded as one of the foremost speakers.

Lecture: "Ferronickel-

Thermodynamics, Chemistry, and Economics"

"I feel privileged to have had a career in pyrometallurgy that exposed me to many commodities, technologies, and countries, and I am grateful to have worked with many wonderful and inspiring people. Participation in international technical conferences has enriched my life greatly and has enabled the two-way sharing of information that allows the industry and the people within it to grow and develop. Numerous valuable friendships have grown from this too. In becoming a recipient of this award, I am humbled to be in the company of so many truly great metallurgists that have gone before me."

\section{EPD DISTINGUISHED SERVICE AWARD}

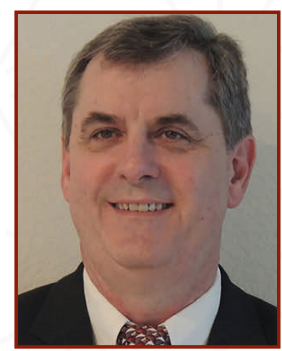

\section{Andreas Siegmund}

Principle, LanMetCon LLC

Citation: In recognition of selfless

service to the Extraction \& Processing

Division, the global nonferrous industry, and his 20 years'leadership of the international Lead-Zinc

symposium.

"It is a great honor to receive this distinguished award from the EPD of TMS. I would like to thank my nominator, Joe Grogan, and the entire EPD for selecting me as this year's recipient. It has been a pleasure to participate in multiple committee functions within EPD and to be part of co-organizing several conferences on behalf of TMS over the last 25 years. This award will always remind me of my long professional association with TMS, EPD, and the gained friendships with many of its members."

\section{EPD SCIENCE AWARD}
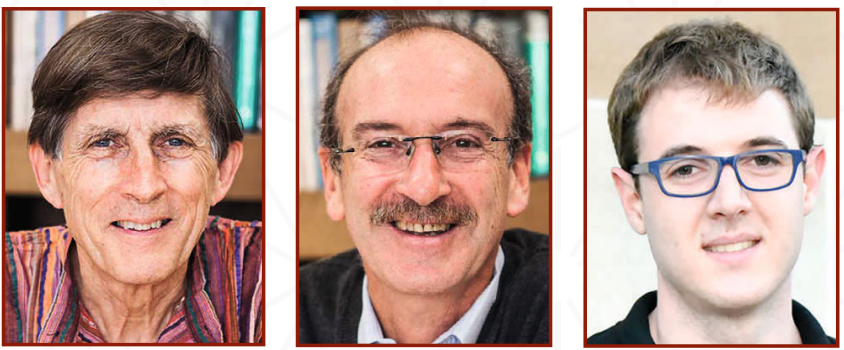

Pictured, left to right: Peter Hayes, Professor, University of Queensland (UQ); Evgueni Jak, Director, UQ; and Suart Nicol, R\&D Engineer, Gopher Resource/UQ

Paper: "Microstructure Evolution During Controlled Solidification of ' $\mathrm{Fe}_{2} \mathrm{O}_{3}$ '- $\mathrm{CaO}-\mathrm{SiO}_{2}$ Liquids in Air," Metallurgical and Materials Transactions B, December 2019.

"I am honored to have been recognized by the EPD for my work. It is rewarding to see my work being viewed by others as having advanced the science of extractive metallurgy and benefiting industrial operations," said Nicol. "Recognition of the importance of the fundamental research on thermodynamics and phase equilibria by colleagues - professionals in the field - is very valuable to me personally and to the whole team. We believe the metallurgy and recycling industry is undergoing a significant 
transformation towards quantitative scientifically—based description of complex processes and, therefore, opening further opportunities for improvements and optimization of industrial operations. This award is valuable to encourage further progress," Jak added. "We live in a period of dramatic changes in technologies, and the expanding use and application of metals in these advanced technologies. We need to continue our research efforts in this field to support the supply of critical raw materials as we seek ways to develop a sustainable society," said Hayes.

\section{EPD TECHNOLOGY AWARD}
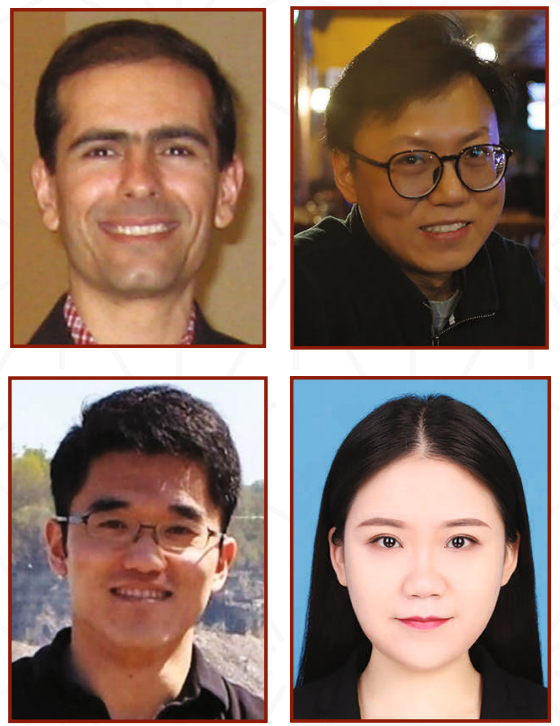

Pictured, left to right: Mansoor Barati, Professor, University of Toronto ( $U$ of T); Feng Liu, Student, $\boldsymbol{U}$ of T; Dawei Yu, Professor, Central South University; and Jiajing Zhang, Associate Director, Capitech Venture Capital Co. Ltd. Paper: "Thermal Upgrading of Nickeliferous Pyrrhotite Tailings for the Recovery of Nickel in the Form of Ferronickel Alloy," Metallurgical and Materials Transactions B, October 2019. "It is a great honor to be the recipient of the TMS EPD Technology Award, which is a high recognition of our previous work on the pyrometallurgical extraction of nickel," said Yu. "TMS provides a great platform for us to communicate and network. Through this platform, great ideas are exchanged, which further advances the field," Liu added. "It is rewarding to see the recognition of this work and the students working on the project. I am grateful to TMS for its multi-faceted contributions to elevating our discipline, running high-quality conferences, publishing top metallurgical journals, and forming a vibrant technical community," Barati said.

\section{EPD PYROMETALLURGY BEST PAPER AWARD}
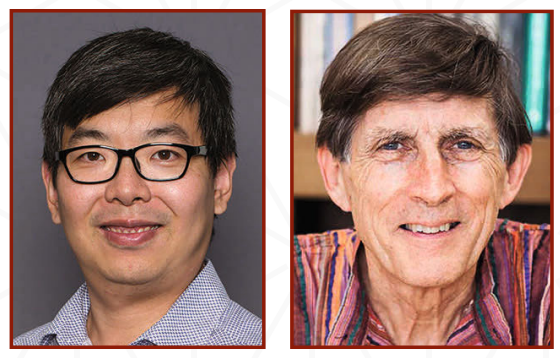

Jiang Chen, Australian

National

University, and

Peter Hayes,

Professor,

University of

Queensland

Presentation:

"Mechanisms and Kinetics of Reduction of Solid NiO in $\mathrm{CO} / \mathrm{CO}_{2}$ and $\mathrm{CO} / \mathrm{Ar}$ Gas Mixtures," Metallurgical and Materials Transactions B, December 2019.

"I'm very honored to receive this award for our recent publication. I'd like to thank everyone who has supported this research work, Akbar Rhamdhani as the paper recommender, and the EPD Pyrometallurgy Committee for choosing our paper for this award. This award is an enormous encouragement for me to continue to contribute to the metallurgy research community," said Chen. "Thanks to the TMS EPD awards committee for this honor. I think it is important that we continue to provide new fundamental scientific information to enhance our knowledge and research capability. For me, breaking new ground is exciting and it is rewarding to know that others working in this field value this research," Hayes added.

\section{FUNCTIONAL MATERIALS DIVISION (FMD) JOHN BARDEEN AWARD}

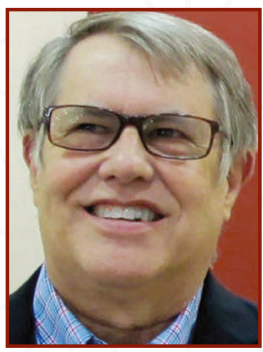

James R. Chelikowsky

W.A. "Tex" Moncrief Jr. Chair of Computational Materials, University of Texas at Austin

Citation: For his leadership and pioneering contributions within the science of electronic materials.

"I am deeply honored to receive this award, especially one named for John

Bardeen, a true icon of condensed matter physics. His fundamental work on surfaces and interfaces continues to be an ongoing inspiration in my career. I am truly humbled to be included within the group of previous winners whose body of work encompasses some of the best science in electronic materials. TMS deserves credit for its tireless work in promoting the science and technology of materials." 


\section{FMD DISTINGUISHED SCIENTIST/ ENGINEER AWARD}

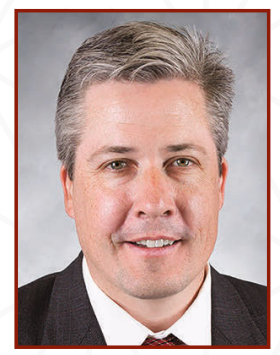

\section{Michael E. Manley}

Senior Researcher, Oak Ridge

National Laboratory

Citation: For experimental research on thermophysical properties of materials at high temperatures, and the discovery of intrinsic localized modes in anharmonic materials.

"I am thrilled and honored to receive this award. I was first introduced to TMS as a graduate student in 1997 and have remained involved ever since. The connections and friendships forged through TMS have played a vital role in my career. I am enthusiastic about engaging in TMS activities for many years to come."

\section{LIGHT METALS DIVISION (LMD) DISTINGUISHED SERVICE AWARD}

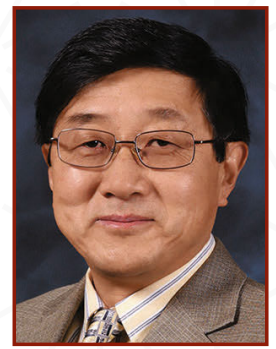

\author{
Alan Luo \\ Professor \& Director, \\ The Ohio State University \\ Citation: For outstanding contributions \\ to the light metals industry and \\ sustained services to LMD and TMS. \\ "I am honored to receive the \\ Distinguished Service Award from the \\ LMD which has been my home division
}

since joining TMS as a graduate student about 30 years ago. I really appreciate my colleagues and friends at TMS and in the LMD for their support and recognition of my work with LMD. I will continue to advance light metals technology and educate the next generation of engineers and researchers for the light metals community."

\section{EPD/LMD JOURNAL OF SUSTAINABLE METALLURY BEST PAPER AWARD}

Mikael Lindvall, SSAB AB; Janice Bolen, Lily Lai Chi So, Mahdi Mahdi, Darryl Metcalfe, and Isabelle Nolet, Hatch Ltd.; Sina Mostaghel, SNC-Lavalin; Johannes Nell, Tronox; and Olle Sundqvist, AB Sandvik Materials Technology

Paper: "Stabilization of Stainless Steel Slag via Air Granulation," Journal of Sustainable Metallurgy, February 2019.

\section{LIGHT METALS SUBJECT AWARDS}

The following awards recognize individual excellence of papers presented at the previous year's TMS annual meeting in an LMD-sponsored session.

\section{Aluminum Alloys}

Anthony De Luca, Empa - Swiss Federal Laboratories for Materials Science and Technology; David Dunand, David Seidman, and Shipeng Shu, Northwestern University

Paper: "Effects of Mn and Mo Micro-additions on Al-ZrSc-Er-Si Mechanical Properties," Light Metals 2020.

\section{Aluminum Reduction Technology}

David LaJambe and Jayson Tessier, Alcoa; and Eric Poulin and Carl Duchesne, Laval University Paper: "Anodic Incident Detection Through Multivariate Monitoring of Individual Anode Current Signals," Light Metals 2020.

\section{Electrode Technology}

Les Edwards and Maia Hunt, Rain Carbon Inc.; and Christopher Kuhnt, Rain Carbon Germany GmbH Paper: "Anhydrous Carbon Pellets-An Engineered CPC Raw Material," Light Metals 2020.

\section{Warren Peterson Cast Shop for Aluminum Production}

Ragnhild Aune, Kai Erik Ekstroem, Catherine

Kyung Won Solem, and Gabriella Tranell, Norwegian University of Science and Technology

Paper: "Evaluation of the Effect of $\mathrm{CO}_{2}$ Cover Gas on the Rate of Oxidation of an AlMgSi Alloy," Light Metals 2020.

\section{LMD MAGNESIUM TECHNOLOGY AWARDS}

The following celebrate individual excellence of papers published in the previous year's volume of Magnesium Technology on specific topics or presented during the TMS annual meeting at the Magnesium Technology Symposium.

\section{Application}

Jan Bohlen, Karl-Ulrich Kainer, Gerrit Kurz, Dietmar Letzig, and Maria Nienaber, Helmholtz-Zentrum Geesthacht Paper: "Variation of Extrusion Process Parameter for the Magnesium Alloy ME21,” Magnesium Technology 2020.

\section{Fundamental Research}

Taylor Cain and Joseph P. Labukas, U.S. Army Research Laboratory

Paper: "Development of Ultra Lightweight, Corrosion Resistant Mg Alloys," Magnesium Technology 2020.

\section{Student Paper}

Trevor B. Abbott, RMIT University; Yahia Ali, Manijn Kim, Stuard D. McDonald, and Kazuhiro Nogita, University of Queensland

Paper: "The Independent Effects of Cooling Rate and $\mathrm{Na}$ Addition on Hydrogen Storage Properties in Hypo-Eutectic Mg Alloys," Magnesium Technology 2020.

\section{Best Poster}

Irene Beyerlein, Claire Weaver, and Shuozhi Xu, University of California, Santa Barbara; Abigail Hunter, Los Alamos National Laboratory; and Anil Kumar, airisData Title: "Quantifying Dislocation Behaviour in Mg Using a Phase Field Dislocation Dynamics Model Multiple Active Slip Planes" 
LMD LIGHT METALS AWARD
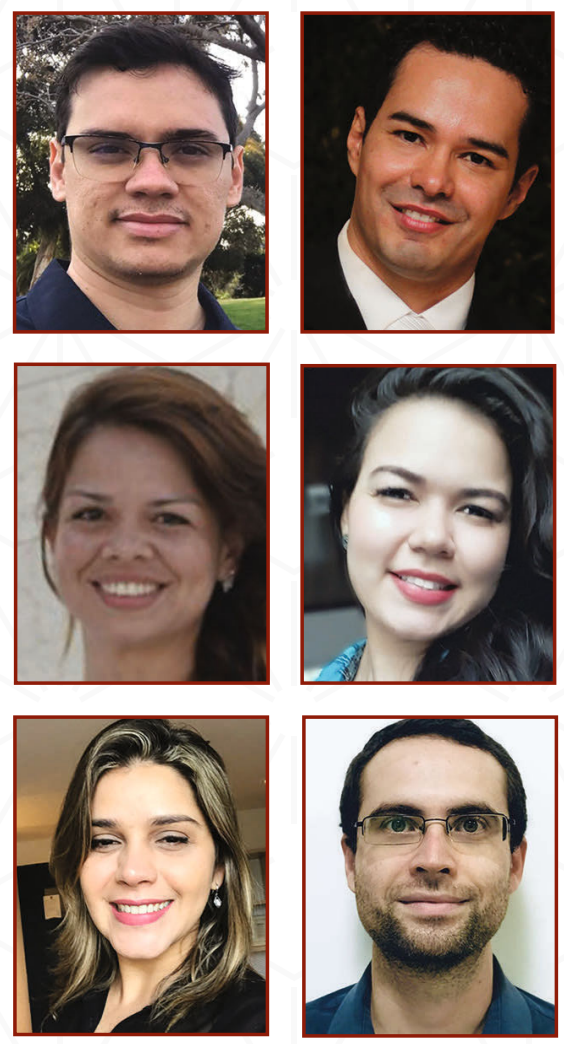

Montini, Norsk; Raphael Vieira de Costa, Norsk;

Roseanne Barata Holanda, Research Assistant, SENAI Innovation Institute for Mineral Technology (ISi-TM); Alice Ferreira Cardoso, Undergraduate Intern, ISi-TM; Adriano Lucheta, Director, ISi-TM; Patricia Magalhães Pereira Silva, Research Assistant, ISi-TM; and Andre Luiz Vilaça do

\section{Carmo, Research Assistant, ISi-TM}

Paper: "Bayer Process Towards the Circular Economy-Soil Conditioners from Bauxite Residue," Light Metals 2020.

"We are very proud to receive this award. The SENAI Innovation Institute for Mineral Technologies (ISi-TM) is in its fifth year of existence and being recognized by TMS associates and peers is a great honor. The ISi-TM and Norsk Hydro Brasil R\&D teams are working hard on the development of sustainable solutions to promote bauxite residue use, and to receive these awards indicates we are on the right path," said Lucheta.

\section{LMD TECHNOLOGY AWARD}

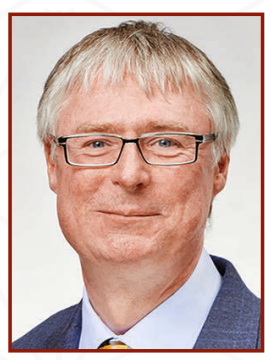

\section{Norbert Hort}

Helmholtz-Zentrum Geesthacht

Citation: For outstanding contributions to research and development in the area of magnesium technology.

\section{MATERIALS PROCESSING \& MANUFACTURING DIVISION (MPMD) DISTINGUISHED SERVICE AWARD}

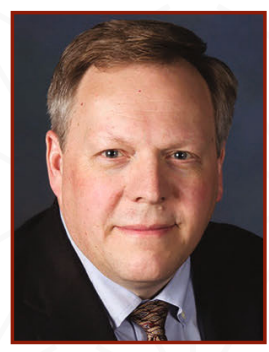

\section{James C. Foley}

Group Leader, Los Alamos National Laboratory

Citation: For exemplary service to MPMD and TMS through leadership of the MPMD Council, the TMS Program Committee, and our Society. "It is a great pleasure to be recognized by my peers for the contributions I

have made to the MPMD and TMS. I hope that my service to the MPMD inspires others to continue to advance the profession and TMS like the past recipients of this award have inspired me. I look forward to my continued interactions with the current leaders of the MPMD and witnessing the development of future leaders of the division. Thank you to all who have contributed to my success."

\section{MPMD DISTINGUISHED SCIENTIST/ ENGINEER AWARD}

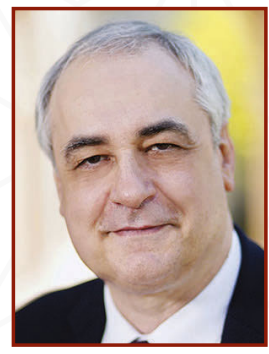

\section{Eugene A. Olevsky}

Dean \& Distinguished Professor, San Diego State University

Citation: For outstanding contributions to materials engineering education and sintering research including development of the modern sintering theories and fundamental studies of field-assisted powder consolidation technologies.

"I am extremely proud and honored to receive this award. TMS is one of the oldest and broadly internationally recognized professional societies in materials engineering. TMS activities are very important for me, my colleagues, and my students. I am very grateful to my nominator and the members of the MPMD Nominations \& Awards Committee for granting me this prestigious distinction!"

\section{STRUCTURAL MATERIALS DIVISION (SMD) DISTINGUISHED SCIENTIST/ ENGINEER AWARD}

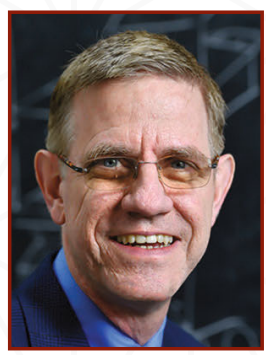

\section{Kevin Hemker}

Professor and Chair,

Johns Hopkins University

Citation: For pioneering work in quantifying the underlying atomic, nano-, and microstructural details that govern the mechanical response, performance and reliability of materials. 


\section{SMD DISTINGUISHED SERVICE AWARD}

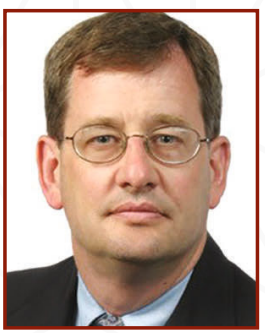

\section{Eric Huron}

Manager, Structural Materials

Development, GE Aircraft Engines

Citation: For providing distinguished service to the structural superalloys community over the past thirty years through his leadership of TMS conferences and symposia.

"I am so grateful for this award because it was made possible by collaboration and teamwork with many TMS colleagues, rather than any individual contribution by me. I have been very fortunate to work with peers who are highly competent materials professionals from industry, academia, and government agencies. I find these collaborations highly satisfying and effective. I encourage all members of TMS, throughout their career, to take advantage of these peer networks and work together to both advance their own learning and career experiences as well as strengthening the entire materials engineering community in the process. My thanks to TMS, my colleagues, and the SMD for the nomination and award."

\section{LMD/EPD ENERGY BEST PAPER AWARDS}

These awards recognize the individual excellence of a paper exemplifying the application of science in solving a practical problem, and therefore must be technological in nature and present new and significant information related to an energy topic.

\section{Professional}

Zhihe Dou, Chao Lv, Ting-an Zhang, and Qiuyue Zaho, Northeastern University

Paper: "Simulation of Process and Reactor Structure Optimization for $\mathrm{CeO}_{2}$ Preparation from Jet-Flow Pyrolysis," JOM, May 2019.

Xiaoxiao Geng and Hao Wang, University of Science and Technology Beijing; Asad Ullah, Karakoram International University Gilgit; Weihua Xue, Liaoning Technical University; Song Xiang, Guizhou University; Li Meng, Central Iron and Steel Research Institute; and Guang Ma, Global Energy Interconnection Research Institute Co. Ltd. Paper: "Prediction of Continuous Cooling Transformation Diagrams for Ni-Cr-Mo Welding Steels via Machine Learning Approaches," JOM, February 2020.

\section{Student}

Joseph Litrel, Electric Boat; Donna Post Guillen, Idaho National Laboratory; and Michael McKellar, University of Idaho

Paper: "Investigation of Performance Enhancements for Air Brayton/ORC Combined Cycles for Small ( 2 MWe) Power Systems and a Moderate Heat Source Temperature," JOM, May 2019.

Bing Li, Vilas Pol, and Vikas Tomar, Purdue University; Thomas Adams, Naval Surface Warfare Center; and Corey Love, U.S. Naval Research Laboratory Paper: "Integrated Sensor Network and Battery Management System for State of Health Estimation and Safety Control of Lithium-ion Batteries"

\section{EPD MATERIALS CHARACTERIZATION AWARDS}

The following awards acknowledge the individual excellence of papers published or posters presented on the topic of materials characterization.

\section{Best Paper Award - First Place}

Virginia Bertolo, Quanxin Jiang, and Vera Popovich, Delft University of Technology; and Carey Walters, Structural Dynamics, TNO

Paper: "Effect of Microstruture on Cleavage Fracture of Thick Section Quenched and Tempered S690 High Strength Steel," Characterization of Minerals, Metals, and Materials 2020.

\section{Best Paper Award - Second Place}

Ramasis Goswami, Naval Research Laboratory; Tanjore Jayaraman and Ganesh Varma Thotakura, University of Michigan-Dearborn

Paper: "Influence on the Structural and Magnetic Properties of the Pre-alloyed Gas-atomized Maraging Steel Powder During Mechanical Milling," Characterization of Minerals, Metals, and Materials 2020.

\section{Best Poster Award - First Place}

Marc de Graef, Maxwell Li, Nisrit Pandey, and Vincent Sokalski, Carnegie Mellon University

Title: "Observation of Topological Defects in Synthetic Antiferromagnets with Inverted Dzyaloshinskii-moriya Interaction"

\section{Best Poster Award - Second Place}

Wesley Higgins and George Pharr, Texas A\&M University Title: "High Strain Rate Nanoindentation of Single Crystalline Metals"

\section{Best Poster Award - Third Place}

Hiroto Ishii, Tokyo Electric Power Company Holdings Inc.; Ken Kurosaki, Kyoto University; Hiroaki Muta and Yuji Ohishi, Osaka University; and Masayoshi Uno, University of Fukui

Title: "Wettability of Liquid Phase Caesium Compounds Against Metal Oxides Including $\mathrm{UO}_{2}$ and ThO"

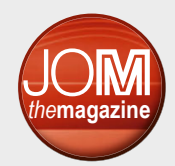

